\title{
Assessment of grip-motion characteristics in carpal tunnel syndrome patients using a novel finger grip dynamometer system
}

Toru Sasaki ${ }^{1}$, Koji Makino², Akimoto Nimura ${ }^{3}$, Shiro Suzuki ${ }^{3}$, Tomoyuki Kuroiwa', Takafumi Koyama', Atsushi Okawa' ${ }^{1}$ Hidetsugu Terada ${ }^{4}$ and Koji Fujita ${ }^{1 *}$ (D)

\begin{abstract}
Background: Grip strength measurement is widely used in daily medical practice, and it has been reported that the grip strength decreases in patients with carpal tunnel syndrome (CTS). However, conventional grip dynamometers evaluate only the maximum power of total grip strength and cannot measure the time course of grip motion. In this report, we aimed to determine the grip characteristics of CTS patients by measuring the time course of each finger's grip motion and to analyze the relationship between finger grip strength and subjective symptoms using this new grip system.
\end{abstract}

Methods: The grip strength of each finger was measured using the new grip system that has four pressure sensors on the grip parts of each finger of the Smedley grip dynamometer. We analyzed the time course of grip motion and relationship between finger grip strength and subjective symptoms in 104 volunteer and 51 CTS hands. The Japanese Society for Surgery of the Hand version of the Carpal Tunnel Syndrome Instrument (CTSI-JSSH) and the Disability of Arm, Shoulder, and Hand questionnaire (DASH) were used as subjective evaluation scores.

Results: In the CTS group, the grip time with the index, middle, and ring fingers was longer, and the time at which strength was lost after reaching the maximum was earlier. Patients with severe subjective symptoms tended to not use the index and middle fingers during grip motion.

Conclusions: This new system that measures each finger's grip strength at one time and record the time course of grip motion could quantify a patient's symptoms easily and objectively, which may contribute to the evaluation of hand function.

Keywords: Carpal tunnel syndrome, Grip dynamometer, Grip motion, Principal component analysis

\footnotetext{
* Correspondence: fujiorth@tmd.ac.jp

'Department of Orthopaedic and Spinal Surgery, Graduate School of Medical and Dental Sciences, Tokyo Medical and Dental University, 1-5-45, Yushima, Bunkyo-ku, Tokyo 113-8519, Japan

Full list of author information is available at the end of the article
}

(c) The Author(s). 2020 Open Access This article is licensed under a Creative Commons Attribution 4.0 International License, which permits use, sharing, adaptation, distribution and reproduction in any medium or format, as long as you give appropriate credit to the original author(s) and the source, provide a link to the Creative Commons licence, and indicate if changes were made. The images or other third party material in this article are included in the article's Creative Commons licence, unless indicated otherwise in a credit line to the material. If material is not included in the article's Creative Commons licence and your intended use is not permitted by statutory regulation or exceeds the permitted use, you will need to obtain permission directly from the copyright holder. To view a copy of this licence, visit http://creativecommons.org/licenses/by/4.0/. The Creative Commons Public Domain Dedication waiver (http://creativecommons.org/publicdomain/zero/1.0/) applies to the data made available in this article, unless otherwise stated in a credit line to the data. 


\section{Background}

Grip strength measurement is widely used in daily medical practice because it is a non-invasive, quick, and inexpensive way of assessing muscle strength. In the field of hand surgery, grip strength may decrease due to pain and neuropathy; thus, it is important to measure the grip strength to evaluate hand function [1-3]. In particular, it has been shown that grip strength is decreased in patients with carpal tunnel syndrome (CTS) [4, 5], which is a clinical syndrome of numbness, pain, and disorder of thumb opposition associated with localized compression of the median nerve at the wrist [6-9]. However, the grip characteristics of patients with CTS are still unclear, and the mechanism underlying diminished grip strength in those with damaged sensory and motor fibers of the median nerve needs to be investigated.

A conventional grip dynamometer, which has been used in many studies that have demonstrated weakened grip strength in patients with CTS, evaluates only the maximum power in the total grip strength of all fingers. Moreover, there have been no reports about the time course of grip motion, such as the time from the beginning of grip motion to maximum power and the time from maximum power to loss of grip strength. Thus, it was necessary to develop a grip dynamometer that can measure the time course to clarify the characteristics of grip motion in CTS patients.

Although the Japanese Society for Surgery of the Hand version of the Carpal Tunnel Syndrome Instrument (CTSI-JSSH) and the Disability of Arm, Shoulder, and Hand questionnaire (DASH) are used as subjective evaluation scores in CTS patients, and the usefulness of these scores as indicators of patient's symptom has been reported [10], there is no report on the correlation between subjective symptoms of CTS and grip strength. To evaluate the subjective symptoms of patients with only distal median nerve dysfunction using a grip dynamometer, we needed a new system for measuring the grip strength of each finger, since it is difficult to accurately evaluate these symptoms using the total grip strength of all fingers.

Therefore, we developed a new grip system that could measure the grip strength of each finger in a single instance to record the time course and analyze the grip motion of healthy volunteers [11]. In this report, to understand the pathophysiology of CTS, we aimed to analyze the grip characteristics of CTS patients by measuring the time course of the grip motion, and we sought to determine the relationship between finger grip strength and subjective symptoms using this new grip system.

\section{Methods}

This study was approved by the institutional review board of our institution, and we obtained informed consent from all patients.

\section{Participants}

We included 51 hands of 30 patients with CTS (bilateral CTS-21, unilateral CTS-9) who were diagnosed by hand surgeons (CTS group) and 104 hands of 52 healthy volunteers (control group). The inclusion criteria for this study were as follows: clinical symptoms of CTS (numbness, tingling, and pain), positive examination for CTS including a positive Phalen's sign and Tinel's sign, and an abnormal nerve conduction study (NCS) with sensory nerve conduction velocity $(\mathrm{SCV})$ of $\leq 44 \mathrm{~m} / \mathrm{s}$ or abductor pollicis brevis-distal latency (APB-DL) of > $4.0 \mathrm{~ms}$. Patients who continued to have symptoms and an abnormal NCS after carpal tunnel release were included. Patients were excluded from this study if they had compressive neuropathy in the ipsilateral arm or peripheral polyneuropathy, cervical disease, DeQuervein syndrome, or trigger finger, had a history of a distal radial fracture, were pregnant, and were non-Japanese speaking. The NCS results were classified according to the Bland classification, which is based on the electrophysiological severity [12].

For the control group, the inclusion criteria included participants who had no symptoms or previous history of neuropathies or trauma to the upper limbs, and they were age-matched to the participants in the CTS group.

\section{Measurement}

The grip strength of each finger was measured using the new grip system developed in our institution. The apparatus used and measurement posture were the same as those in the previous report, and data regarding the healthy volunteers have already been reported [11]. The structure of this system was the same as that in the previous report and is shown in Fig. 1. This system consists of three units, which are as follows: a measurement unit with four pressure sensors on the grip parts of each finger (index, middle, ring, and little fingers) of the Smedley grip dynamometer (Fig. 1a), a wireless communication unit that sends the data to the display every $10 \mathrm{~ms}$, and a display unit that shows each finger's grip strength in real time (Fig. 1b). When the patients grip this system, the four sensors measure the voltage values and send the data to the display through a wireless communication unit. The voltage values are converted to grip strength, and each finger's grip strength is displayed and saved on the computer in real time.

The right and left finger grip strengths were measured twice $[13,14]$ using this system while the patient was 
(a)

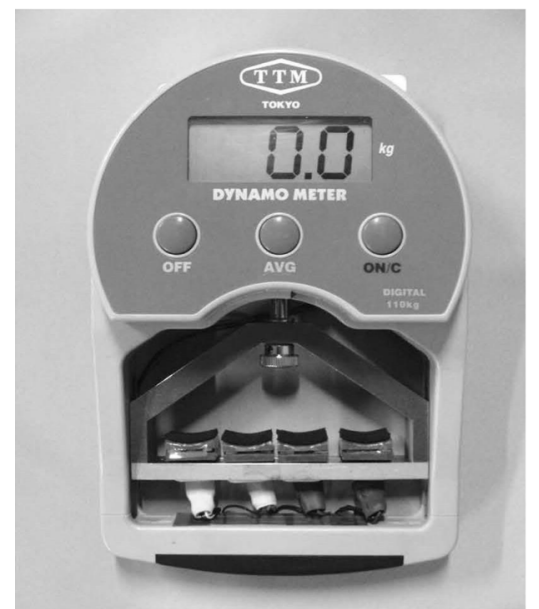

(b)

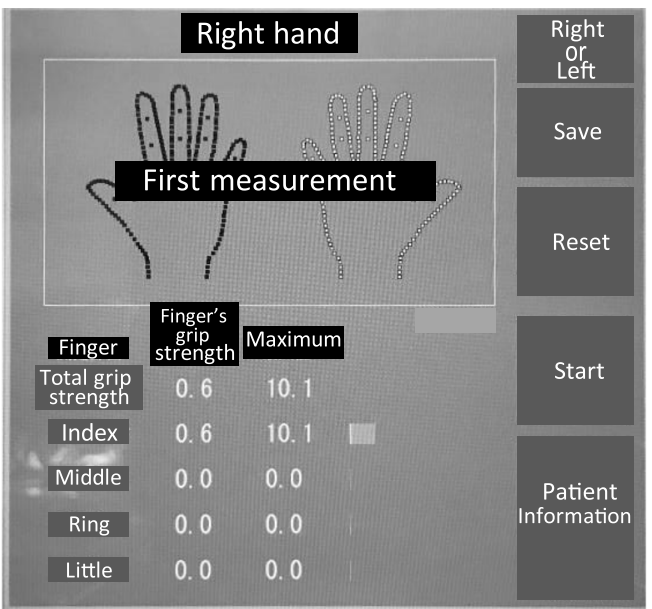

Fig. 1 The finger grip dynamometer system. a Measurement unit: four pressure sensors on the grip parts of each finger (index, middle, ring, and little fingers) of the Smedley grip dynamometer. The four sensors measure the voltage values and send the data to the display through a wireless communication unit. b Display unit: the display converts measuring date to grip strength and shows date in real time

standing with the shoulders adducted, elbows in the straight position, and forearms and wrists in the neutral position. The average of the two trials was calculated. The patients were instructed to hold the device as hard and as early as possible and to release it when the power reached the maximum.

\section{Statistical analysis}

Data regarding age, CTSI-JSSH, DASH, and measured grip strength are presented as medians with interquartile ranges. The Student $t$ test, Fisher exact test, and MannWhitney $U$ tests were used to compare differences in nominal and nonparametric variables. Based on previous studies, we considered a $3.0-\mathrm{kg}$ decrease in the grip strength as clinically meaningful when comparing the difference in grip strength between the CTS patients and controls $[15,16]$. We calculated that, with a sample of 88 participants (44 participants per group), the study would have $80 \%$ power to detect a $3.0-\mathrm{kg}$ mean decrease in the grip strength, with a type 1 error of $5 \%$. For the power analysis, we used a standard deviation of 5.0 in the grip strength using data reported in previous studies [17]. To evaluate the characteristics of grip motion in the CTS patients, we performed the following types of analysis.

First, to compare the time course of finger grip strength between the CTS and control groups, the grip time at which the maximum grip strength was reached was analyzed. We calculated the time from reaching $20 \%$ of the maximum strength to reaching the maximum strength $[18,19]$. We compared the grip time between the CTS and control groups using $t$ tests. In addition, we analyzed the mechanism underlying the diminished grip strength in CTS patients. The ratio of the maximum finger grip strength to real time finger grip strength was considered to be the $\Delta$ Grip strength. We calculated $\Delta$ Grip strength from -1.6 to $+3.2 \mathrm{~s}$ of the time when the maximum grip strength was reached. At each time point, the average of $\triangle$ Grip strength of the CTS and control groups was calculated and visualized graphically for each finger. Since the absolute values of each finger's grip strength were not being compared, differences in gender and individual physique have less of an influence on the grip time and $\Delta$ Grip strength.

Second, to evaluate the relationship between subjective symptoms and finger grip strength in CTS patients, a principal component analysis (PCA) of each finger's grip strength and subjective symptom scores was performed in the CTS group. PCA is a multivariate statistical technique applied to systematically reduce the number of dimensions [20-22]. This method extracts the important information from the data to represent these data as a set of new orthogonal variables called principal components and to display the pattern similarity between the observations and the variables as points in maps. PCA results show that factors with arrows pointing in the same direction have a tendency to be correlated, while factors with scattered arrows have little correlation. In the PCA, we set the grip strength of the individual's largest finger (index, middle, ring, or little finger) to 1.0 and calculated the ratio of the other fingers to that of the largest finger. PCA of their finger grip strength ratios and subjective scores was performed. For this reason, our results compare of the ratio of forces per finger; thus, it was not affected by differences in individual physique. The subjective symptom score was obtained 
using the CTSI-JSSH symptom severity scale (CTSI-SS), CTSI-JSSH functional condition scale (CTSI-FS), and DASH. In order to investigate the characteristics of body size, we performed PCA on body mass index (BMI) and finger grip strength.

\section{Results}

The participants' demographic features are presented in Table 1.

\section{Time course of each finger's grip strength}

Grip time with the index, middle, and ring fingers was longer in the CTS group than in the control group (Fig. 2). However, there was no difference in grip time with the little finger between the two groups. In particular, a significant difference $(P=0.01)$ was observed in the grip time of the middle finger.

Furthermore, in the time course of $\Delta$ Grip strength of the middle and ring fingers, the CTS group showed an early loss of strength after reaching the maximum grip strength than the control group (Fig. 3). In the time course of the little finger, the CTS group tended to release later than the control group. For the index finger, there was no difference between the CTS and control groups.

\section{Principal component analysis}

The results of the PCA of the subjective symptom score and each finger's grip strength in the CTS group were examined. In the PCA of each finger's grip strength and CTSI-SS, CTSI-SS was drawn between the ring and little fingers and showed a strong correlation with the ring finger (Fig. 4). In the PCA of each finger's grip strength and CTSI-FS, CTSI-FS was drawn between the ring and little fingers and showed a strong correlation with the little finger, similar to the PCA of DASH (Figs. 5 and 6). In the PCA of each finger's grip strength and BMI, the arrows of little finger grip strength and BMI pointed same direction (Fig. 7).

\section{Discussion}

In this study, we analyzed the characteristics of grip motion in CTS patients and examined the relationship between grip strength and subjective symptoms (CTSIJSSH and DASH) using a new grip system that can measure each finger's grip strength at a single instance and record the time course of grip motion.

There have been no reports focused on the time course of grip motion, such as the time from the beginning of grip motion to the maximum power, and the time from maximum power to loss of grip strength. Our system could show the characteristics of CTS patients in whom the grip time of the index, middle, and ring fingers was long, and grip strength was lost early after it reached the maximum. In the little finger, the CTS group tended to release later than the control group. This may be due to the fact that the middle and ring fingers are released early in the CTS group and rely on the little finger for gripping. From these results, we may be able to quantitatively evaluate sensory and motor nerve disorders, which may affect the hand function of CTS patients.

Table 1 Characteristics of the participants in the CTS and control groups

\begin{tabular}{|c|c|c|c|}
\hline & Control group $(N=52)$ & $\begin{array}{l}\text { CTS group }(N=51) \\
\text { Pre-operation }=40 \\
\text { Post-operation }=11\end{array}$ & $p$ value \\
\hline Sex & & & $0.288^{*}$ \\
\hline Male & 19 & 13 & \\
\hline Female & 33 & 38 & \\
\hline Age & $70(58-79)$ & $73(61-78.3)$ & $0.35^{* *}$ \\
\hline Bland classification & & $\begin{array}{l}\text { Grade 0,1 } \\
\text { Grade 1,7 } \\
\text { Grade 2,3 } \\
\text { Grade 3, } 17 \\
\text { Grade 4, } 0 \\
\text { Grade 5, } 14 \\
\text { Grade 6,9 }\end{array}$ & \\
\hline CTSI-SS & & $22(16-25)$ & \\
\hline CTSI-FS & & $37.0(27.5-37.5)$ & \\
\hline DASH & & $37.1(22.0-41.2)$ & \\
\hline
\end{tabular}

Data are presented as median (IQR). Statistical significance was determined by the Fisher exact test and Mann-Whitney $U$ test.

IQR interquartile range, CTS carpal tunnel syndrome,

CTSI-SS Japanese Society for Surgery of the Hand version of Carpal Tunnel Syndrome Instrument Symptom Severity Scale, CTSI-FS Japanese Society for Surgery of the Hand version of Carpal Tunnel Syndrome Instrument Functional Condition Scale, DASH Disabilities of the Arm Shoulder and Hand, BMI body mass index *Fisher's exact test

**Mann-Whitney $U$ tests 


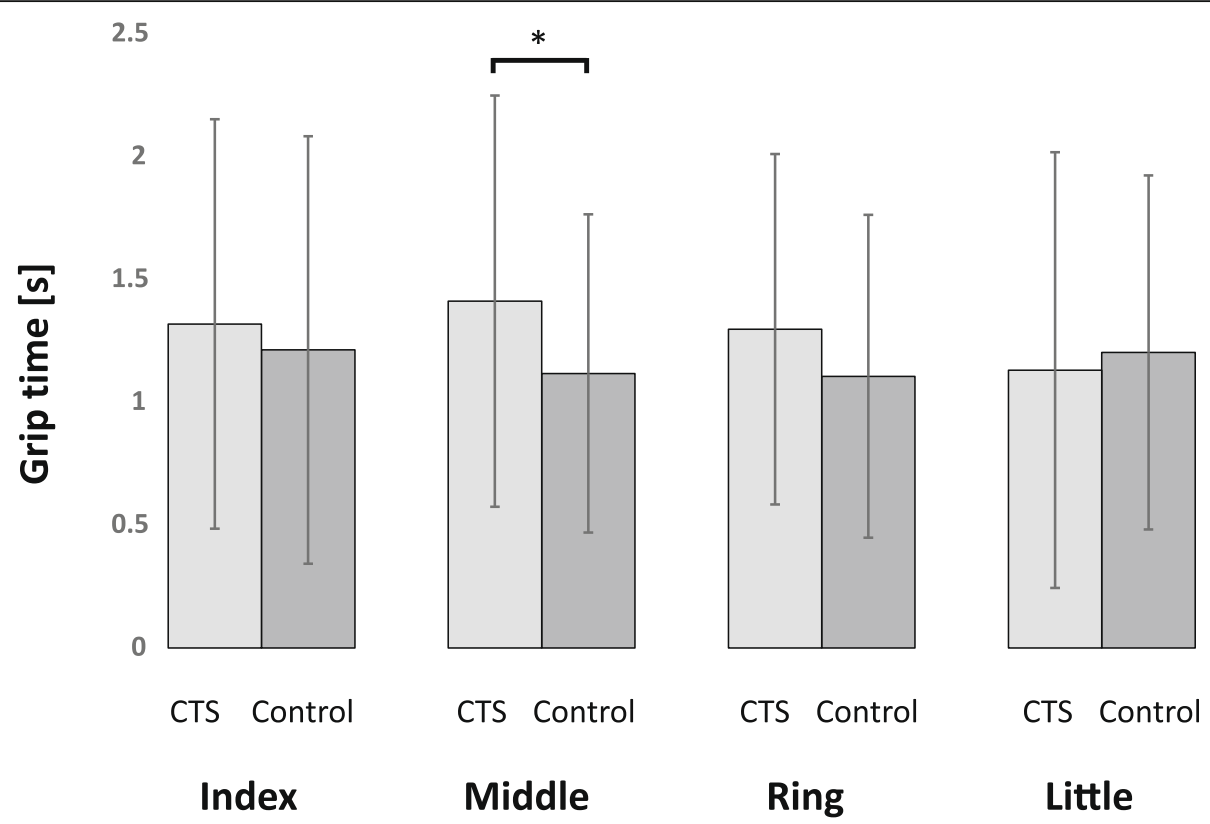

Fig. 2 Grip time of each finger's grip strength. Grip time with index, middle, and ring fingers is longer in the CTS patients than in the controls. Statistical significance was determined by using the Student $t$ test. In the grip time with the middle finger, a significant difference is observed between the CTS patients and controls $(P=0.01)$

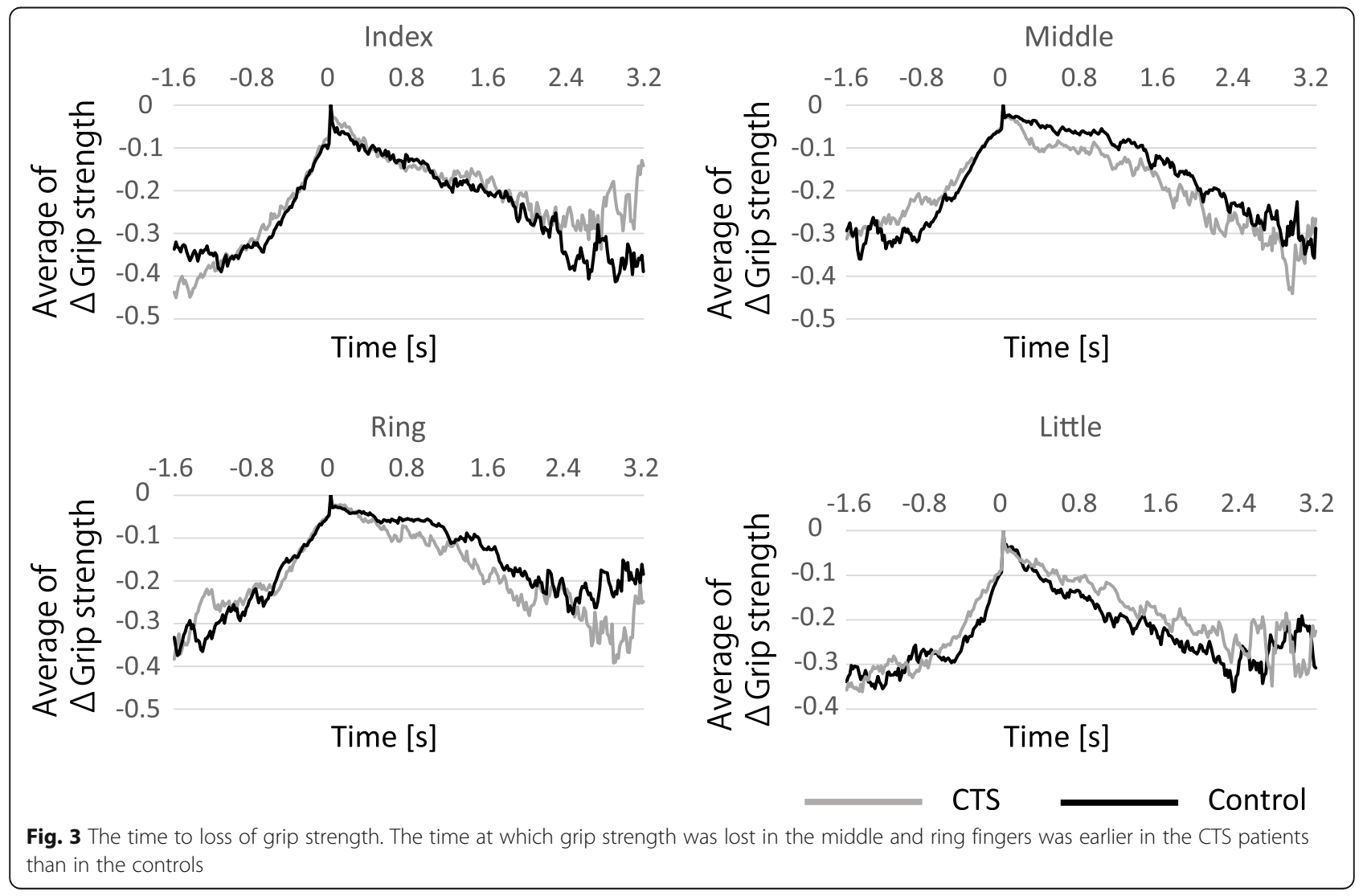




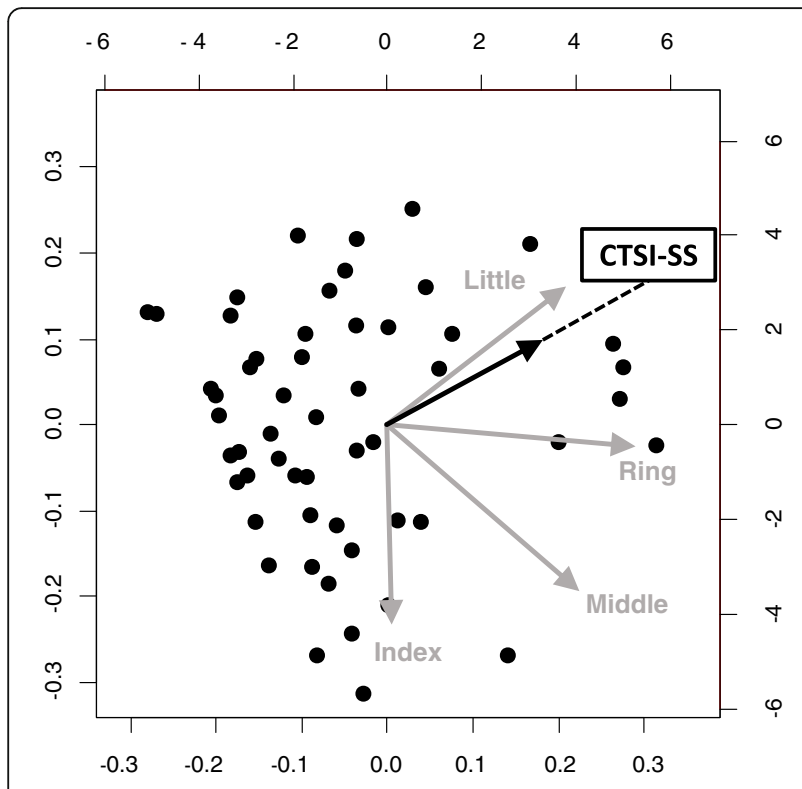

Fig. 4 Result of the PCA of each finger's grip strength and CTSI-SS

Furthermore, a grip system was previously used to measure the maximum grip strength of each finger of healthy hands with anesthesia to the median nerve [23]. In that report, grip strength of the middle, ring, and little fingers decreased after anesthesia, which was not consistent with the pathophysiology of CTS; thus, this method, using anesthesia, was deemed inadequate to accurately evaluate the hand function of CTS patients. Conversely, in our study, the symptom severity correlated with the tendency of patients to not use the index and middle fingers during grip motion. These results were consistent with the pathophysiology of CTS.

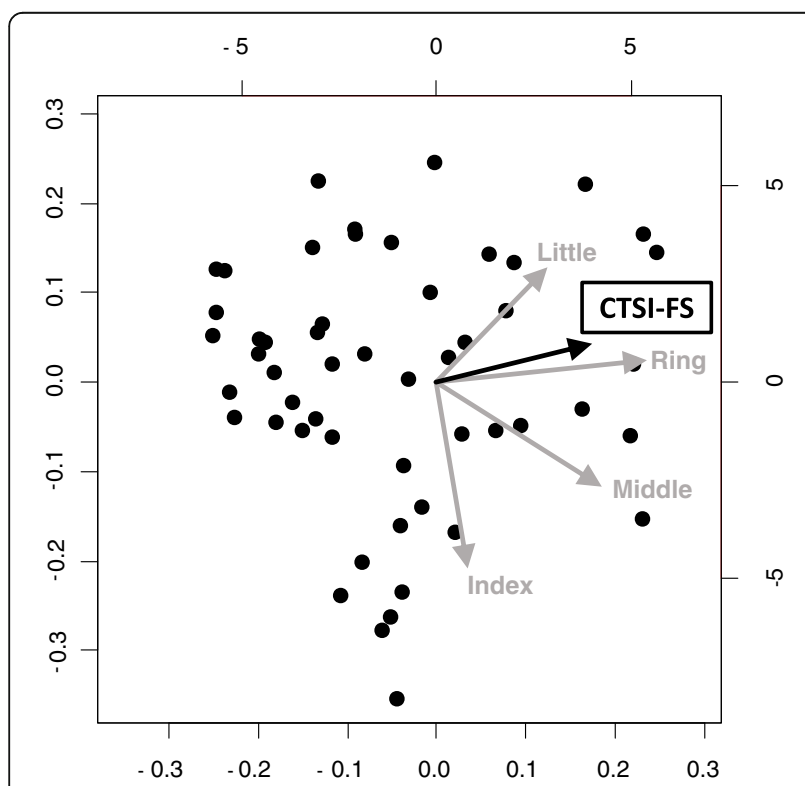

Fig. 5 Result of the PCA of each finger's grip strength and CTSI-FS

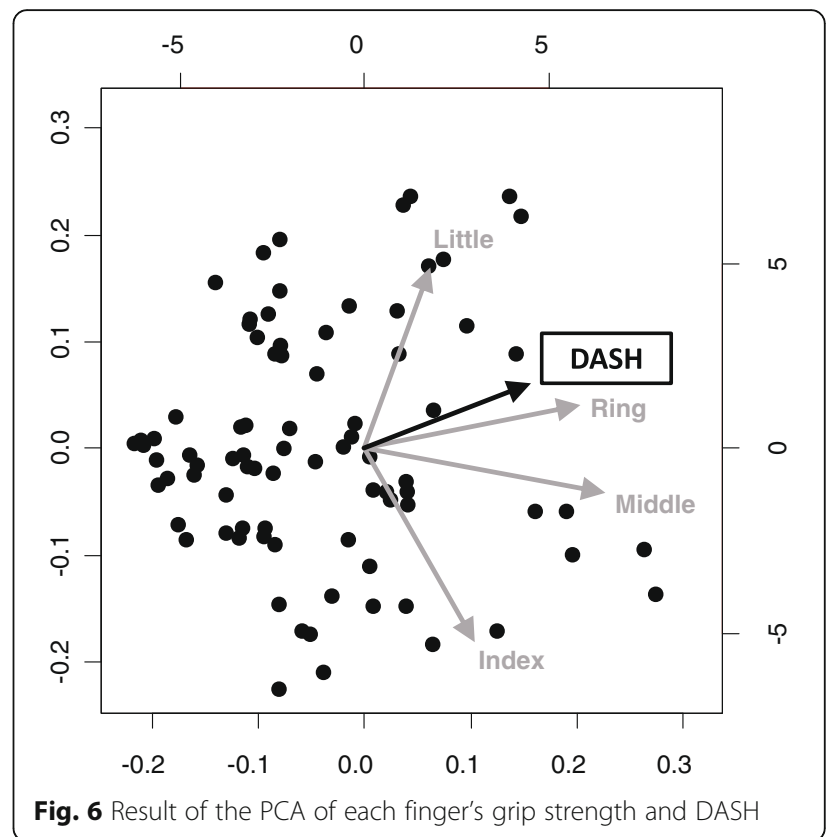

A previous study using a conventional grip dynamometer reported that no correlation was found between grip strength and severity of CTS [24]. It was also demonstrated that grip motion requires a synergistic function of the intrinsic and extrinsic muscles of the hand and does not use the muscles affected by CTS [25]. Thus, the conventional grip dynamometer may not be accurate enough to evaluate the function of the hands with CTS. Conversely, in our PCA for CTSI-FS, CTSI-SS, DASH, and finger grip strength, the arrow was shown between the ring and little finger. In the PCA, factors with arrows pointing in the same direction have a tendency to be

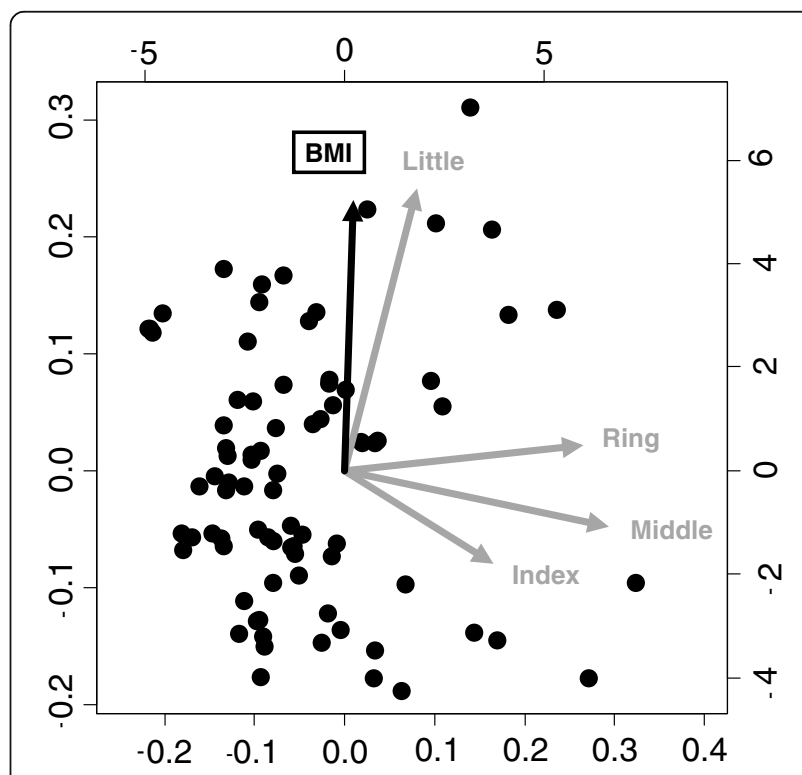

Fig. 7 Result of the PCA of each finger's grip strength and BMI 
correlated. These results show that patients with severe subjective symptoms, as well as high CTSI-FS, CTSI-SS, and DASH scores, tended to not use the index and middle fingers during grip motion. These results proved that the function of the index and middle fingers worsens when the sensory nerve fibers of the digital nerve (index, middle, and ring fingers) and motor nerve fibers of the first and second lumbricals are damaged at the carpal tunnel. Thus, the finger grip dynamometer system could become a useful tool for evaluating the severity of CTS. It is not clear why patients with a high BMI are more likely to hold their little finger. In a study using a conventional grip strength dynamometer, people with a higher BMI were found to have greater grip strength [26]; thus, people with stronger grip strength may tend to grip on the ulnar side. We also analyzed the SCV and APB-DL of the NCS as an objective evaluation. Although PCA was performed on SCV, APB-DL, and finger grip strength, none showed a correlation between electrophysiological severity and finger grip strength (data not shown).

This study has several limitations. First, the CTS and control groups matched in age but not in sex. Although the comparison of the absolute value of the total grip strength and each finger's grip strength is inadequate, the analysis of time course and the PCA were not evaluations of the absolute value of grip strength and were considered to be useful results. Second, because DASH is not a questionnaire that asked for answers on the left and right hand separately, DASH results do not necessarily reflect the subjective symptoms of hands measured by finger grip strength. CTSI is a questionnaire that asks for answers on the left and right hands separately.

\section{Conclusion}

We developed a new grip system that can measure each finger's grip strength at a single instance and record the time course of grip motion. Our system could show the characteristics of CTS patients in whom the grip time of the index, middle, and ring fingers was long, and grip strength was lost early after it reached the maximum. Furthermore, we could show that patients with severe subjective symptoms tended to not use the index and middle fingers during grip motion. From these results, our system could quantify the patient's symptoms easily and objectively. To measure each finger's grip strength in real time is an unprecedented method for characterizing the grip motion of patients with various diseases and understanding the pathophysiology of diseases. In the future, we would like to evaluate whether this finger grip dynamometer system is useful for diagnosis.

\section{Abbreviations}

ABP-DL: Abductor pollicis brevis-distal latency; CTS: Carpal tunnel syndrome; CTSI-FS: CTSI-JSSH functional condition scale; CTSI-JHSS: Japanese Society for Surgery of the Hand version of the Carpal Tunnel Syndrome DASHDisability of Arm, Shoulder, and Hand questionnaire; CTSI-SS: CTSI-JSSH symptom severity scale; NCS: Nerve conduction study; PCA: Principal component analysis; SCV: Sensory conduction velocity

\section{Acknowledgements}

We would like to thank Editage (www.editage.jp) for the English-language editing.

\section{Authors' contributions}

T.S. and K.M. performed all experiments and analyses and prepared the first draft of the paper. K.F. designed the study, collected patient data, and supervised the project. He is the guarantor. A.N., S.S., T.Kuroiwa, and T.Koyama collected the patients' data and provided advice about the experimental conditions. A.O. and H.T. provided advice about the experimental conditions. All authors read and approved the final manuscript.

\section{Funding}

This work was supported by JST AIP-PRISM Grant Number JPMJCR18Y2, Japan.

\section{Availability of data and materials}

The datasets used and/or analyzed during the current study are available from the corresponding author on reasonable request.

\section{Ethics approval and consent to participate}

This comparative study was approved by the Tokyo Medical and Dental University institutional review board (M2017-123).

\section{Consent for publication}

Not applicable.

\section{Competing interests}

The authors declare that they have no competing interests.

\section{Author details}

${ }^{1}$ Department of Orthopaedic and Spinal Surgery, Graduate School of Medical and Dental Sciences, Tokyo Medical and Dental University, 1-5-45, Yushima, Bunkyo-ku, Tokyo 113-8519, Japan. ${ }^{2}$ Center for Creative Technology, University of Yamanashi, 4-3-11, Takeda, Kofu, Yamanashi, Japan. ${ }^{3}$ Department of Functional Joint Anatomy, Graduate School of Medical and Dental Sciences, Tokyo Medical and Dental University, 1-5-45, Yushima, Bunkyo-ku, Tokyo 113-8519, Japan. ${ }^{4}$ Department of Mechatronics, University of Yamanashi, 4-3-11, Takeda, Kofu, Yamanashi, Japan.

Received: 29 January 2020 Accepted: 30 June 2020

Published online: 06 July 2020

\section{References}

1. Bot AGJ, Mulders MAM, Fostvedt S, Ring D. Determinants of grip strength in healthy subjects compared to that in patients recovering from a distal radius fracture. J Hand Surg Am. 2012;37:1874-80.

2. Czitrom AA, Lister GD. Measurement of grip strength in the diagnosis of wrist pain. J Hand Surg Am. 1988, 9:13a16.

3. Edmunds JO. Current concepts of the anatomy of the thumb trapeziometacarpal joint. J Hand Surg Am. 2011;36:170-82.

4. Baker NA, Moehling KK, Desai AR, Gustafson NP. Effect of carpal tunnel syndrome on grip and pinch strength compared with sex- and agematched normative data. Arthritis Care Res. 2013;65:2041-5.

5. Yucel $\mathrm{H}$. Factors affecting symptoms and functionality of patients with carpal tunnel syndrome: a retrospective study. J Phys Ther Sci. 2015;27: 1097-101.

6. Fujita K, Kimori K, Nimura A, Okawa A, Ikuta Y. MRI analysis of carpal tunnel syndrome in hemodialysis patients versus non-hemodialysis patients: a multicenter case-control study. J Orthop Surg Res. 2019;14:91.

7. Kuroiwa T, Fujita K, Nimura A, Miyamoto T, Sasaki T, Okawa A. A new method of measuring the thumb pronation and palmar abduction angles 
during opposition movement using a three-axis gyroscope. J Orthop Surg Res. 2018;13:288.

8. Kuroiwa T, Nimura A, Suzuki S, Sasaki T, Okawa A, Fujita K. Measurement of thumb pronation and palmar abduction angles with a small motion sensor: a comparison with Kapandji scores. J Hand Surg Eur Vol. 2019;44:728-33.

9. Werner RA, Andary M. Electrodiagnostic evaluation of carpal tunnel syndrome. Muscle Nerve. 2011;44:597-607.

10. Uchiyama S, Imaeda T, Toh S, Kusunose K, Sawaizumi T, Wada T, et al. Comparison of responsiveness of the japanese society for surgery of the hand version of the carpal tunnel syndrome instrument to surgical treatment with dash, sf-36, and physical findings. J Orthop Sci. 2007;12: 249-53.

11. Makino K: Development of a dynamometer to measure grip strength of each finger. 2018 IEEE 27th International Symposium on Industrial Electronics.

12. Bland JD. A neurophysiological grading scale for carpal tunnel syndrome. Muscle Nerve. 2000;23:1280-3.

13. Coldham F, Lewis J, Lee H. The reliability of one vs. Three grip trials in symptomatic and asymptomatic subjects. Journal of Hand Therapy. 2006;19: 318-27.

14. Watanabe T, Owashi K, Kanauchi Y, Mura N, Takahara M, Ogino T. The shortterm reliability of grip strength measurement and the effects of posture and grip span. J Hand Surg-Am. 2005:30a:603-9,

15. Jeong S, Kim J. Prospective association of handgrip strength with risk of new-onset cognitive dysfunction in korean adults: a 6-year national cohort study. Tohoku J Exp Med. 2018;244:83-91.

16. Wolny T, Linek P, Saulicz E. Assessment of manual dysfunction in occupationally active women with carpal tunnel syndrome. Int I Occup Med Environ Health. 2019;32:185-96.

17. Atkinson HH, Rapp SR, Williamson JD, Lovato J, Absher JR, Gass M, et al. The relationship between cognitive function and physical performance in older women: results from the women's health initiative memory study. J Gerontol A Biol Sci Med Sci. 2010;65:300-6.

18. Merletti R, Holobar A, Farina D. Analysis of motor units with high-density surface electromyography. J Electromyogr Kinesiol. 2008;18:879-90.

19. Peng Y, He J, Yao B, Li S, Zhou P, Zhang Y. Motor unit number estimation based on high-density surface electromyography decomposition. Clin Neurophysiol. 2016;127:3059-65.

20. Gray RJ, Thom M, Riddle M, Suh N, Burkhart T, Lalone E. Image-based comparison between the bilateral symmetry of the distal radii through established measures. J Hand Surg Am. 2019;44:966-72.

21. Luria S, Schwarcz Y, Wollstein R, Emelife P, Zinger G, Peleg E. 3-dimensional analysis of scaphoid fracture angle morphology. J Hand Surg Am. 2015;40: 508-14

22. Sollaccio DR, Navo P, Ghiassi A, Orr CM, Patel BA, Lewton KL. Evaluation of articular surface similarity of hemi-hamate grafts and proximal middle phalanx morphology: a 3D geometric morphometric approach. J Hand Surg Am. 2019;44:121-8.

23. Kozin SH, Porter S, Clark P, Thoder JJ. The contribution of the intrinsic muscles to grip and pinch strength. J Hand Surg Am. 1999:24:64-72.

24. Atalay NS, Sarsan A, Akkaya N, Yildiz N, Topuz O. The impact of disease severity in carpal tunnel syndrome on grip strength, pinch strength, fine motor skill and depression. J Phys Ther Sci. 2011;23:115-8.

25. Geere J, Chester R, Kale S, Jerosch-Herold C. Power grip, pinch grip, manual muscle testing or thenar atrophy - which should be assessed as a motor outcome after carpal tunnel decompression? A systematic review. BMC Musculoskelet Disord. 2007:8:114

26. Jeong SM, Choi S, Kim K, Kim SM, Kim S, Park SM. Association among handgrip strength, body mass index and decline in cognitive function among the elderly women. Bmc Geriatr. 2018;18.

\section{Publisher's Note}

Springer Nature remains neutral with regard to jurisdictional claims in published maps and institutional affiliations.

Ready to submit your research? Choose BMC and benefit from:

- fast, convenient online submission

- thorough peer review by experienced researchers in your field

- rapid publication on acceptance

- support for research data, including large and complex data types

- gold Open Access which fosters wider collaboration and increased citations

- maximum visibility for your research: over $100 \mathrm{M}$ website views per year

At BMC, research is always in progress.

Learn more biomedcentral.com/submissions 